\title{
Leaf plasticity and stomatal regulation determines the ability of Arundo donax plantlets to cope with water stress
}

\author{
A. ROMERO-MUNAR ${ }^{+}$, E. BARAZA, J. CIFRE, C. ACHIR, and J. GULÍAS \\ Research Group on Plant Biology under Mediterranean Conditions. Department of Biology. University of the Balearic \\ Islands, Ctra. Valldemossa, Km. 7.5. 07122, Palma de Mallorca, Spain
}

\begin{abstract}
The objective of this study was to evaluate the response of the giant reed (Arundo donax L.) to drought stress at early stages, as well as to determine the effects of limited soil water availability on plant growth, gas exchange, and water-use efficiency. Plantlets of a commercial clone were grown in a greenhouse under two water treatments: at $100 \%$ of field capacity and progressive drought for 66 days (until $20 \%$ of field capacity). Soil water content, leaf elongation rate, plant water consumption, and gas-exchange parameters were measured throughout the experiment. Total plant biomass, leaf water, and osmotic potential were determined at the end of the experiment. Plant growth and leaf gas-exchange parameters were significantly affected by soil water availability, but only when it was below $40 \%$ of field capacity. At early stages, Arundo donax showed drought stress acclimation due to leaf plasticity, stomatal regulation, and osmotic adjustment.
\end{abstract}

Additional key words: early stage; osmotic potential; stomatal conductance; water deficit.

\section{Introduction}

Arundo donax (giant reed) is a perennial grass found in several regions throughout the world that has been proposed as a potentially high-yielding non-food crop under Mediterranean conditions (Arcidiacono and Porto 2012, Pilu et al. 2013, Sánchez et al. 2015). It is a rhizomatous $\mathrm{C}_{3}$ grass species that shows a high growth capacity, and it is used to colonize several different soil conditions, especially flooded areas (Bell 1997). The interest in this grass as a biomass source is based on its high biomass production under the low fertility conditions of Mediterranean areas and on its interesting second generation biofuel production (Pilu et al. 2012, Scordia et al. 2012). Moreover, its cropping life has been reported to be approximately $12-15$ years with low maintenance costs due to low fertilizer and pesticide requirements (Pilu et al. 2013). Indeed, in addition to non-food crops, the use of marginal lands has been highlighted as a key point for biofuels sustainability. Although the concept of marginal land is under debate and may have different implications world- wide, it seems to be accepted that producing biomass under low water and fertilizer inputs in lands that are not currently used for agricultural production may be a sustainable source of bioenergy (Kang et al. 2013, Shortall 2013).

The Mediterranean climate is characterized by a strong seasonal variability in precipitation (Paredes et al. 2006) with severe summer droughts that last for two to six months and cool wet winters. In a climate change scenario, a decrease in the annual number of precipitation days in Mediterranean regions has been predicted (Stocker et al. 2013). In this region, more than $60 \%$ of the water resources are used for irrigation to meet crop water requirements. The giant reed shows potential traits to develop climatic tolerance to different abiotic stresses (Mann et al. 2013, Pilu et al. 2013). However, although it is well known that once established $A$. donax is highly drought tolerant (Perdue 1958, Lewandowski et al. 2003, Lambert and Dudley et al. 2010), water availability during the first year after plantation, when the root system is still

Received 21 September 2016, accepted 19 January 2017, published as online-first 21 March 2017.

${ }^{+}$Corresponding author; phone: +34 971172 525, fax: +34 971173 184, e-mail: antonia.romero@uib.cat

Abbreviations: $C_{\mathrm{c}}-$ chloroplastic $\mathrm{CO}_{2}$ concentration; $\mathrm{Chl}-$ chlorophyll; $C_{\mathrm{i}}-$ substomatal $\mathrm{CO}_{2}$ concentration; DAT - days after transplantation; FC - field capacity percentage; $g_{\mathrm{s}}$ - stomatal conductance; $g_{\mathrm{m}}-$ mesophyll conductance; $\mathrm{H}_{2} \mathrm{O}_{\mathrm{c}}-$ total water consumption; $J_{\max }$ - the potential light- saturated electron transport rate; $J_{\text {flu }}-$ the electron transport rate; $P_{\mathrm{N}}-$ net photosynthetic rate; $R_{\mathrm{D}}$ - respiration rate in the light; $R_{\mathrm{n}}$ - the respiratory rate in the absence of light; $V_{\text {cmax }}$ - the maximum Rubisco carboxylation rate; WD - water-stressed; WUE - water-use efficiency; WW - well-watered.

Acknowledgements: This work was financed by the OPTIMA-FP7. A. Romero-Munar was funded by a fellowship of the Government of Balearic Islands and European Social Fund. The authors would like to thank Mr. Miquel Truyols and collaborators of the UIB Experimental Field (UIB Grant 15/2015) for their support to our experiments. 
underdeveloped, considerably limits plant growth and establishment, which endangers its future productivity (Arcidiacono and Porto 2012). Because of these issues, maximizing plant growth and resource-use efficiency at early stages appear to be key factors in ensuring future crop production and sustainability in $A$. donax under Mediterranean conditions. Although research of $A$. donax under water stress conditions has increased in recent years, little attention has been devoted to the study of early plant acclimation mechanisms to cope with drought and the possibilities of increasing water-use efficiency (WUE) at this stage. Sánchez et al. $(2015,2016)$ recently reported that water deficit leads to tight stomatal closure and biomass decrease in different $A$. donax clones that showed lower leaf area ratio and specific leaf area in response to drought. However, little is known about the relationship among soil water availability, stomatal conductance, and biomass accumulation in $A$. donax plantlets. Indeed, no data is available about limitations of photosynthesis machinery under drought stress at early stages. Studies of the biochemical and diffusive parameters regulating the maximum rate of photosynthesis are thus required to explain the basis of the observed changes in photosynthetic

\section{Materials and methods}

Plant material and experimental design: Twenty-four micropropagated plantlets of a commercial clone of giant reed (provided by Piccoplant Inc., Germany) were transplanted into 4-L pots with silicic sand and $25 \mathrm{~g}$ of slow-release fertilizer. All the transplanted plantlets had a similar size, with one tiller and 3-5 expanded leaves. The experimental trial was performed from October to January (during 12 weeks) under greenhouse conditions to avoid rainfall interference. The daily maximum temperatures showed little variation between the beginning and the end of the experiment (approximately $24^{\circ} \mathrm{C}$ ).

The plants were well-watered (at $100 \%$ of field capacity) for $20 \mathrm{~d}$ after transplanting (DAT). Afterwards, twelve plants were kept under well-watered conditions (WW) and twelve were subjected to water-deficit (WD) conditions by a reduction in irrigation levels during 62 DAT [from $100 \%$ to $20 \%$ of field capacity (FC)]. The soil water regime was managed by weighing each pot three times per week and restoring either $100 \%$ or $80 \%$ of the consumed water in WW and WD plants, respectively (Fig. 1), which also allowed the determination of plant water consumption. The progressive WD treatment was imposed by restoring $80 \%$ of water losses until the soil water content achieved $20 \%$ of FC. The pot mass at field capacity was previously determined after watering to saturation and allowing drainage for $24 \mathrm{~h}$. The increase of whole plant mass during the experiment was not considered because it was negligible in comparison to the total pot mass.

Growth and biomass parameters: The leaf elongation rate $\left(P_{\mathrm{N}}\right)$ under water stress conditions. This would allow to understand deeper the $A$. donax physiology during the most limiting moment of its life cycle, and thus maximize plant WUE with little loss of biomass accumulation (Parry et al. 2005). Moreover, the plant osmotic response to water deficit, particularly osmotic adjustment, has been suggested as a useful physiological adaptation to maintain cell turgor at low water potential, which is essential for leaf elongation and plant growth under moderate drought.

The aim of this study was to determine the effects of moderate water deficit at early stages on $A$. donax biomass accumulation, leaf water relations, leaf gas exchange, and WUE. Thus the present study analyzes the mechanisms giant reed uses to cope with water stress at its most limiting stage of plant development. The following specific questions were addressed: (1) How does water deficit affect biomass accumulation and allocation (leaf, shoot and root production)? (2) Is osmotic adjustment a water deficit stress tolerance mechanism in Arundo donax? (3) Is gas exchange constrained by diffusive or nondiffusive limitations under water deficit conditions? (4) Is there an opportunity to maximize the WUE and to minimize the carbon assimilation decrease in $A$. donax plantlets?

rate (mm per day) was determined during the experiment (initial, 0-20 DAT; middle, 30-50 DAT; end, 70-80 DAT) by measuring the length of the youngest leaf of each plant until growth ceased. At the end of the experiment, the plant height, number of leaves per stem, and number of stems per plant were measured.

Each plantlet was separated into stems, roots, and leaves, and was separately dried in an oven. The total dry biomass per plant was determined by summing the aerial dry biomass and the root dry biomass. The shoot-root ratio, leaf mass ratio (LMR) and leaf area ratio (LAR) were also calculated. Three to five total expanded leaves were separately scanned at the moment of destructive analysis and sampling to dry to measure the specific mass and to determine the specific leaf area (SLA) and total leaf area (LA).

Leaf gas exchange and chlorophyll (Chl) $a$ fluorescence: Simultaneous measurements of leaf gas exchange and Chl $a$ fluorescence were conducted from 10:00 to $12: 30 \mathrm{~h}$ on sunny days, twice per week along the experiment on young, fully expanded leaves in all plants. These measurements were performed with an open infrared gasexchange analyzer system ( $\mathrm{Li}$ - 6400; $\mathrm{Li}$-Cor Inc., Lincoln, NE, USA) equipped with a leaf chamber fluorometer (Li-6400-40, Li-Cor Inc.). Measurements were performed under saturating PPFD of $1,500 \mu \mathrm{mol} \mathrm{m}^{-2} \mathrm{~s}^{-1}$, with $10 \%$ of blue light, and a vapor pressure deficit of $2.0-3.0 \mathrm{kPa}$ at a $\mathrm{CO}_{2}$ concentration of $400 \mu \mathrm{mol} \mathrm{mol} \mathrm{m}^{-1}$ (air). The leaf temperature was set at $25^{\circ} \mathrm{C}$, and the relative humidity of the incoming air was approximately $50 \%$ throughout all measurements. The gas-exchange measurements provided 
the net $\mathrm{CO}_{2}$ assimilation $\left(P_{\mathrm{N}}\right)$ and the stomatal conductance $\left(g_{\mathrm{s}}\right)$ of the leaves. The Chl $a$ fluorescence measurements allowed the determination of the photochemical efficiency of PSII $\left(\Phi_{\text {PSII }}\right)$ in the light-adapted stage (Peguero-Pina et al. 2012).

Mesophyll conductance and biochemical photosynthetic parameters: In order to conduct a thorough analysis of drought stress on photosynthesis, maximum Rubisco carboxylation rate $\left(V_{\text {cmax }}\right)$, potential light-saturated electron transport rate $\left(J_{\max }\right)$, leaf dark respiration in the light $\left(R_{\mathrm{D}}\right)$, and mesophyll conductance $\left(g_{\mathrm{m}}\right)$ were estimated as explained below. After inducing steady-state photosynthesis for at least $30 \mathrm{~min}$, the photosynthesis response to varying substomatal $\mathrm{CO}_{2}$ concentration $\left(C_{\mathrm{i}}\right)$ was measured in all samples per treatment as explained in Galmés et al. (2007). Net photosynthesis-response curves to varying substomatal $\mathrm{CO}_{2}$ concentration $\left(P_{\mathrm{N}}-C_{\mathrm{i}}\right)$ consisted of 16 measurements per curve [stepwise in the range of 50-2,000 $\mu \mathrm{mol}\left(\mathrm{CO}_{2}\right) \mathrm{mol}^{-1}$ (air)] and were transformed to $P_{\mathrm{N}}$ vs. chloroplastic $\mathrm{CO}_{2}$ concentration $\left(C_{\mathrm{c}}\right)$ curves $\left(P_{\mathrm{N}^{-}} C_{\mathrm{c}}\right)$ according to Peguero-Pina et al. (2012). The chloroplast $\mathrm{CO}_{2}$-compensation point $\left(\mathrm{r}^{*}\right)$ was estimated as described in Galmés et al. (2007).

Respiratory measurements in the absence of light $\left(R_{\mathrm{n}}\right)$ were measured by placing a leaf in the gas-exchange cuvette, without light source, after $30 \mathrm{~min}$ in the dark (time for transition from light-acclimated to dark-acclimated mitochondrial respiration). $R_{\mathrm{n}}$ was used as a proxy of dark respiration $\left(R_{\mathrm{D}}\right)$ in $P_{\mathrm{N}}-C_{\mathrm{c}}$ curves (Bernacchi et al. 2002, Niinemets et al. 2006). Corrections for the leakage of $\mathrm{CO}_{2}$ into and out of the leaf chamber of the $\mathrm{Li}-6400$ have been applied to all gas-exchange data, as described by Flexas et al. (2007).

Following method by Harley et al. (1992), based on combined gas exchange and $\mathrm{Chl}$ fluorescence, $g_{\mathrm{m}}$ and the chloroplastic $\mathrm{CO}_{2}$ concentration were estimated.

Quantitative analysis of photosynthetic limitation: To determine the quantitative limitation of photosynthesis, $P_{\mathrm{N}}-C_{\mathrm{i}}$ curves were performed as described in supporting information (SI) following the methodology used by different authors (Harley et al. 1992, Bernacchi et al. 2002,

\section{Results}

Evaluation of soil water content and plant water consumption: early response of $\boldsymbol{A}$. donax to soil water content decrease: The soil water content of both WW and WD plants ranged between $80 \%$ of FC from 0 to $20 \mathrm{DAT}$. From 20 DAT, after a progressive drought imposition, the soil water content of WD plants progressively dropped to $20 \%$ of FC at $50 \mathrm{DAT}$, and it was kept at approximately this level until the end of the experiment (Fig. 1). The soil water content differences between treatments were significant from the first day of treatment application (20 DAT),
Niinemets et al. 2006, Flexas et al. 2007, Galmés et al. 2007, Peguero-Pina et al. 2012). $P_{\mathrm{N}}, g_{\mathrm{s}}, g_{\mathrm{sc}}, g_{\mathrm{m}}$, and $V_{\mathrm{cmax}}$ values (obtained from $P_{\mathrm{N}}-C_{\mathrm{i}}$ analysis) were used to calculate the quantitative limitations of photosynthesis following the quantitative limitation analysis of Grassi and Magnani (2005). This method allows the determination of nonstomatal limitations, defined as the sum of the contributions due to mesophyll conductance and leaf biochemistry $\left(\mathrm{NS}_{\mathrm{L}}=\mathrm{MC}_{\mathrm{L}}+\mathrm{B}_{\mathrm{L}}\right)$, and the diffusive limitations, defined as the sum of stomatal and mesophyll conductance components $\left(D_{L}=S_{L}+M C_{L}\right)$. In the present work, the method modified by Grassi and Magnani (2005) was used to quantify the WD effect in each limitation component in comparison with WW conditions. In this sense, the values of each parameter of WW plants were used as a control in this analysis. The values of each parameter used in the quantitative limitation analysis are the mean of 12 plantlets per treatment.

Leaf water and osmotic potential: To determine plant water status at the end of the experiment, the leaf water and osmotic potentials were measured at predawn and midday for each plant at the end of the experiment. The leaf water potential was determined on fully expanded leaves with a Scholander pressure chamber (Soil moisture Equipment Corp., Santa Barbara, CA, USA); afterwards, a portion of each leaf was stored at $-80^{\circ} \mathrm{C}$. The leaf osmotic potential was determined in those samples by using a vapor pressure deficit osmometer (Wescor Inc., Logan, UT, USA).

Water-use efficiency (WUE) was assessed at the leaf and plant levels. The WUE at the leaf level was determined by intrinsic gas-exchange measurements as $P_{\mathrm{N}} / g_{\mathrm{s}}\left(\mathrm{WUE}_{\mathrm{i}}\right.$, $\left.\mu \mathrm{mol} \mathrm{mol}{ }^{-1}\right)$. At the end of the experiment, the WUE at the plant level $\left(\mathrm{WUE}_{\mathrm{p}}, \mathrm{g} \mathrm{L}^{-1}\right.$ ) was calculated as a relation between plant dry biomass production and total water consumption $\left(\mathrm{H}_{2} \mathrm{O}_{\mathrm{c}}\right)$ of each pot during all the experiment.

Statistical analyses: A univariate analysis of variance (ANOVA) and Duncan's test were performed to reveal the differences between groups in the studied parameters. The analyses were performed using $J M P{ }^{\circledR}$, Version $10(S A S$ Institute Inc., Cary, NC, 1989-2007).

which showed a progressive increase of differences along the experiment (Fig. 1). The water consumption increased along the experiment in WW plantlets, while WD ones showed constant values of consumed water. From the day when the treatments were completely imposed (50 DAT), the water consumption was five times higher in WW plantlets than that in the WD plantlets (Table 1). Over the whole experimental period, the WD plantlets consumed $62 \%$ less water than the WW plantlets (Table 1). 


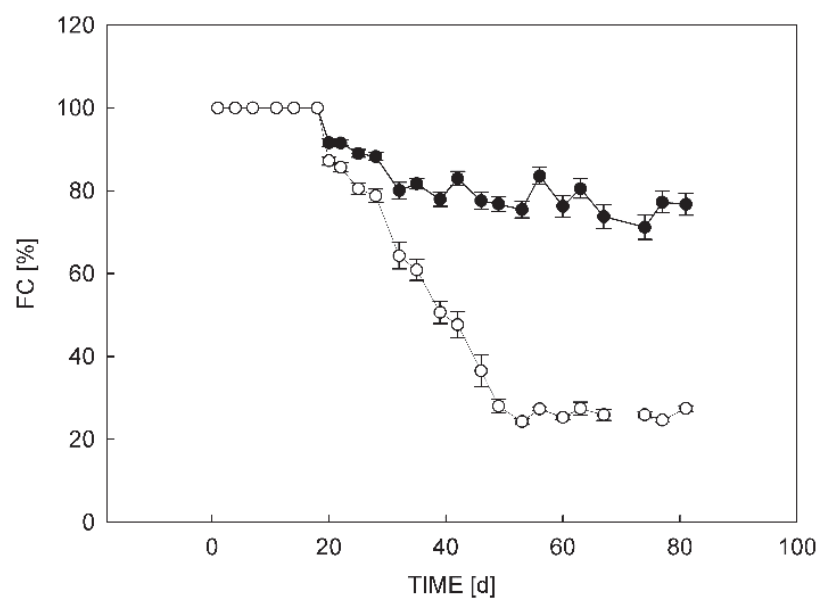

Fig. 1. Evolution over time of the soil water content (expressed as percentage of field capacity, FC) of well-watered plants (black circles) and water-deficit plants (white circles). Values are the means of 12 replicates $\pm \mathrm{SE}$.

Table 1. Plant water consumption of well-watered (WW) and water-deficit (WD) plants throughout the experiment. Values of water consumption are the means of 12 replicates $\pm \mathrm{SE} .{ }^{*}-$ significant differences between treatments at $p<0.05$.

\begin{tabular}{|c|c|c|c|}
\hline Plants & First week & Last week & Whole period \\
\hline WW & $20 \pm$ & $166 \pm$ & $92=$ \\
\hline $\mathrm{WD}\left[\mathrm{ml} \mathrm{d}^{-1}\right]$ & $20 \pm 2.0$ & $29 \pm 3.0^{*}$ & $35 \pm 2.0^{*}$ \\
\hline
\end{tabular}

Growth and biomass parameters: Both leaf length and leaf elongation rate (LER) were affected by the soil water content (Table 2). The WD plants possessed smaller leaves and lower LER than that of the WW plants at the middle and at the end of the experiment when the soil water content was significantly different in both treatments (Table 2).

The biomass production and allocation were affected by the water treatment (Table 3). Under WD conditions, the decrease of total biomass was mostly due to the reduction of shoot biomass because the root biomass was not significantly different between treatments. As a consequence, the shoot to root ratio $(\mathrm{S} / \mathrm{R})$ was significantly higher in the WW plants than that in the WD plants. The leaf area (LA), leaf mass ratio (LMR), leaf area ratio (LAR), and specific leaf area (SLA) were significantly lower in the WD plants than those in the WW plants (Table 3). The LA decrease in the WD plants was mainly due to both the lower number of shoots and the smaller leaves under the WD conditions than under the WW conditions, rather than to the number of leaves per shoot (Tables 2, 3). In spite of the lower biomass production, the WD plants showed a WUE increase $\left(4.39 \pm 0.460 \mathrm{~g} \mathrm{~L}^{-1}\right.$ in $\mathrm{WD}$ and $2.89 \pm 0.268 \mathrm{~g} \mathrm{~L}^{-1}$ in WW plantlets), as a consequence of the relatively high reduction in water consumption under the WD conditions.

Water relations: Both pre-dawn and midday water potential were lower in the WD plants at the end of the

Table 2. Air temperature, soil water content (\% of field capacity, FC), leaf elongation rate (LER) and leaf length at three periods of the experiment: initial (days 0-20), middle (days 30-50), and end (days 70-80). Values are the means of 12 plants \pm SE. Different letters within the same treatment indicate significant differences $(p<0.05)$ between periods. Within the same period, $*$ denotes significant differences $(p<0.05)$ between treatments.

\begin{tabular}{|c|c|c|c|c|c|c|c|}
\hline \multicolumn{2}{|c|}{ Temperature $\left[{ }^{\circ} \mathrm{C}\right]$} & \multirow{2}{*}{$\begin{array}{l}\text { FC [\%] } \\
\text { WW }\end{array}$} & \multirow[b]{2}{*}{ WD } & \multicolumn{2}{|l|}{ LER } & \multicolumn{2}{|l|}{ Leaf length } \\
\hline & & & & WW & WD & WW & WD \\
\hline Initial & 26.36 & $95.79 \pm 0.47$ & $93.59 \pm 0.52$ & $1.23 \pm 0.07^{\mathrm{a}}$ & $1.21 \pm 0.14^{\mathrm{a}}$ & $19.91 \pm 1.35$ & $17.40 \pm 1.25$ \\
\hline Middle & 25.56 & $78.17 \pm 1.80$ & $34.11 \pm 2.21^{*}$ & $1.89 \pm 0.09^{\mathrm{b}}$ & $1.07 \pm 0.16^{\mathrm{a} *}$ & $23.98 \pm 1.14$ & $18.63 \pm 1.72^{*}$ \\
\hline End & 23.56 & $77.90 \pm 2.37$ & $26.05 \pm 0.73^{*}$ & $1.27 \pm 0.18^{\mathrm{a}}$ & $0.37 \pm 0.07^{\mathrm{b} *}$ & $23.78 \pm 1.79$ & $11.70 \pm 0.80^{*}$ \\
\hline
\end{tabular}

experiment (Fig. 2A), when the soil water content was significantly different between treatments. Those differences were higher at midday than at pre-dawn. At midday, the WD plants showed a leaf water potential of $-2.3 \mathrm{MPa}$, whereas the WW plants only reached $-1.2 \mathrm{MPa}$. Plants under both treatments rehydrated at night because both the relative water content (Fig. $2 B$ ) and the leaf water potential were significantly higher at predawn than that at midday. Similarly, the leaf osmotic potential was significantly lower in the WD plants than that in the WW plants at both predawn and midday (Fig. $2 B$ ). At midday, the WD plants showed a leaf osmotic potential of $-2.3 \mathrm{MPa}$, whereas the WW plants reached only $-1.5 \mathrm{MPa}$.
Gas-exchange parameters: The $P_{\mathrm{N}}, g_{\mathrm{s}}$, and $J_{\text {flu }}$ were significantly lower in the WD plants than those in the WW plants during most of the experiment (Fig. 3). However, the effect of the WD was observed in the $g_{\mathrm{s}}$ before the $P_{\mathrm{N}}$. Indeed, the $P_{\mathrm{N}}$ was significantly lower in the WD plants only when the soil water content fell below $40 \%$ FC (20 DAT). In contrast, $g_{\mathrm{s}}$ was significantly different between treatments as soon as the soil water content fell below $60 \%$ of FC (10 DAT). Electron transport rate $\left(J_{\mathrm{flu}}\right)$, was the latest parameter being affected by water stress, significant differences between WD and WW plants were only observed after 47 DAT (Fig. $3 C$ ). In all cases, the differences between treatments increased as the soil water 
content decreased in the WD pots. The estimation of biochemical parameters showed no effect of water deficit on the photosynthetic apparatus because no differences were observed in either $V_{\mathrm{c}, \max }$ or $J_{\max }$ (Table 4). The quantitative limitation analyses revealed that the photosynthesis of the WD plants was mostly limited by

\section{Discussion}

Petroleum and agricultural land scarcity triggered the research based in thesecond generation of biofuels. In this sense, A. donax had been demonstrated good traits regarding its crop productivity and acclimation to different soil conditions (Pilu et al. 2012). Webster et al. (2016) reported that the high productivity of $A$. donax is due to the higher photosynthetic capacity and intrinsic water-use efficiency. However, there is a lack of knowledge on $A$. donax ecophysiology under water-stress conditions that made important crop losses in the first stages of implantation. In this line, the aim of this study was to evaluate the response of $A$. donax to a moderate water deficit at early developmental stages as a critical determinant of the potential use of this species as biomass source for second generation of biofuels in Mediterranean marginal lands. A. donax plantlets showed morphological, anatomical, and physiological changes as a consequence of the water deficit, which led to lower plant water consumption and higher WUE at both the leaf and plant levels. The present study supports the possibility of increasing the WUE with a low biomass decrease in A. donax plantlets during the first year of plantation,

Table 3. Growth and biomass parameters of Arundo donax plantlets grown under well-watered (WW) and water-deficit (WD) conditions. Biomass parameters are reported as dry mass. Height of principal stem; number of stems per plant; stem biomass; number of leaves of the principal stem; total leaf biomass; shoot biomass; root biomass; shoot to root ratio (S/R); specific leaf area (SLA); plant leaf area (LA); leaf mass ratio (LMR); leaf area ratio (LAR). Values are the means of 12 replicates \pm SE. $*$ denotes significant differences between treatments at $p<0.05$.

\begin{tabular}{|c|c|c|}
\hline & WW & WD \\
\hline Height $[\mathrm{cm}]$ & $51.6 \pm 3.64$ & $42.2 \pm 2.47^{*}$ \\
\hline $\mathrm{N}^{\circ}$ of stems & $7.0 \pm 0.60$ & $5.0 \pm 0.50^{*}$ \\
\hline Stem biomass $[\mathrm{g}]$ & $4.25 \pm 0.28$ & $2.04 \pm 0.16^{*}$ \\
\hline $\mathrm{N}^{0}$ of leaves & $14.25 \pm 0.74$ & $12.67 \pm 0.56$ \\
\hline Leaf biomass [g] & $6.38 \pm 0.42$ & $3.46 \pm 0.21^{*}$ \\
\hline Shoot biomass [g] & $10.60 \pm 0.69$ & $5.50 \pm 0.36^{*}$ \\
\hline Root biomass [g] & $5.63 \pm 0.59$ & $4.55 \pm 0.53$ \\
\hline Total biomass [g] & $16.28 \pm 1.17$ & $10.06 \pm 0.84^{*}$ \\
\hline $\mathrm{S} / \mathrm{R}$ & $2.08 \pm 0.16$ & $1.27 \pm 0.11^{*}$ \\
\hline SLA $\left[\mathrm{cm}^{2} \mathrm{~g}^{-1}\right]$ & $238.1 \pm 8.38$ & $184.6 \pm 3.48^{*}$ \\
\hline $\mathrm{LA}\left[\mathrm{cm}^{2}\right]$ & $1525.0 \pm 114.90$ & $0671.4 \pm 37.97^{*}$ \\
\hline $\operatorname{LMR}\left[\mathrm{g} \mathrm{g}^{-1}\right]$ & $0.395 \pm 0.01$ & $0.344 \pm 0.02^{*}$ \\
\hline $\operatorname{LAR}\left[\mathrm{cm}^{2} \mathrm{~g}^{-1}\right]$ & $94.09 \pm 4.26$ & $63.45 \pm 2.86^{*}$ \\
\hline
\end{tabular}

stomatal limitations, which accounted for more than $93.3 \%$ of the total limitations. Biochemical limitations represented $4.7 \%$ of the total limitations, and mesophyll conductance limitations accounted for $2 \%$ of the total limitations.

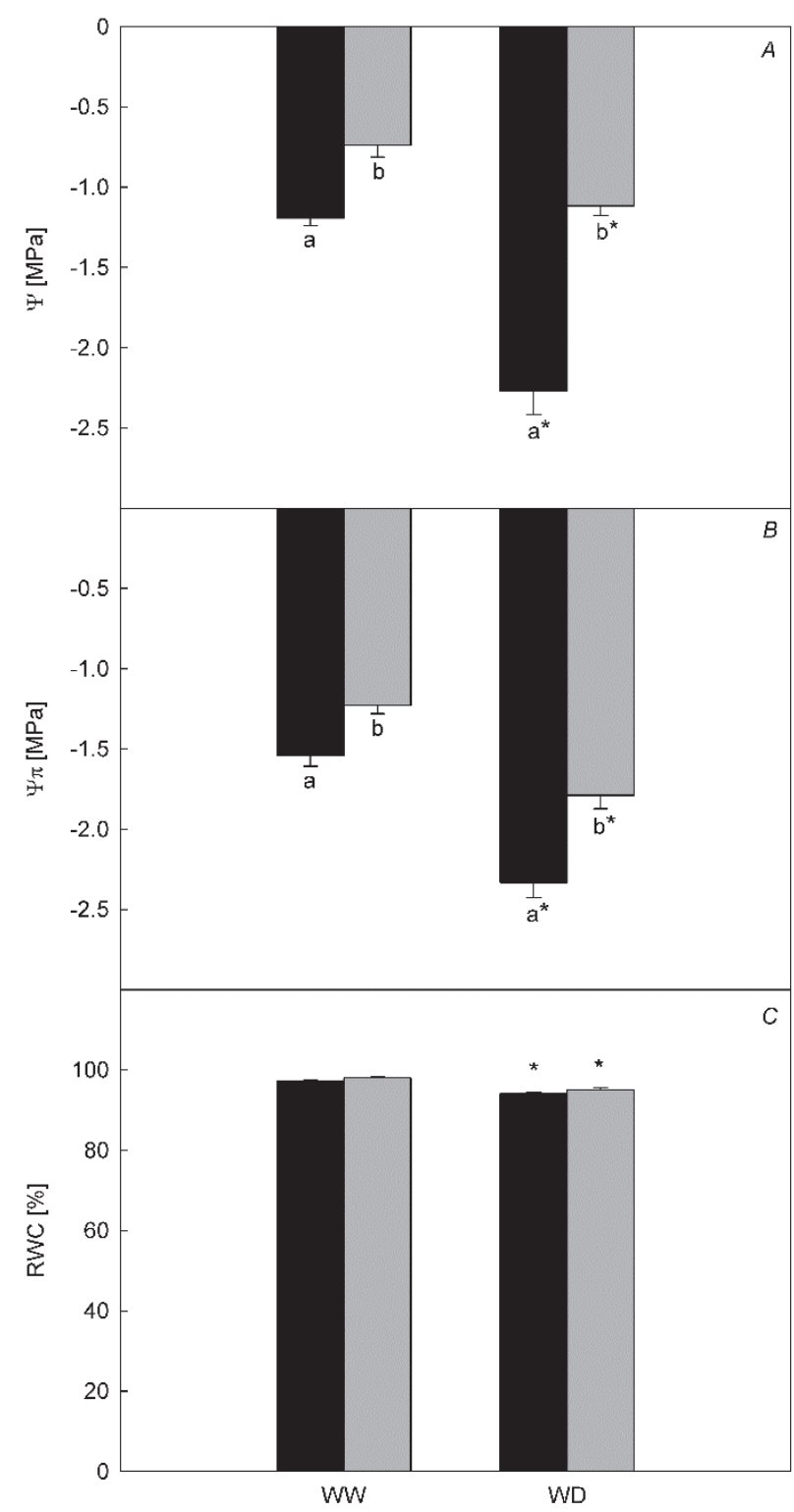

Fig. 2. Leaf water potential $(\Psi, A)$, osmotic potential $\left(\Psi_{\pi}, B\right)$, and relative water content as a percentage (RWC, $C$ ) of Arundo donax under well-watered (WW) and water-deficit (WD) conditions at midday (black bars) and predawn (grey bars) at day 69. Values are the means of 12 replicates \pm SE. Different letters within treatment denote significant differences $(p<0.05)$ between sampling times. ${ }^{*}$ - significant differences $(p<0.05)$ between treatments within the same time of measurement. 


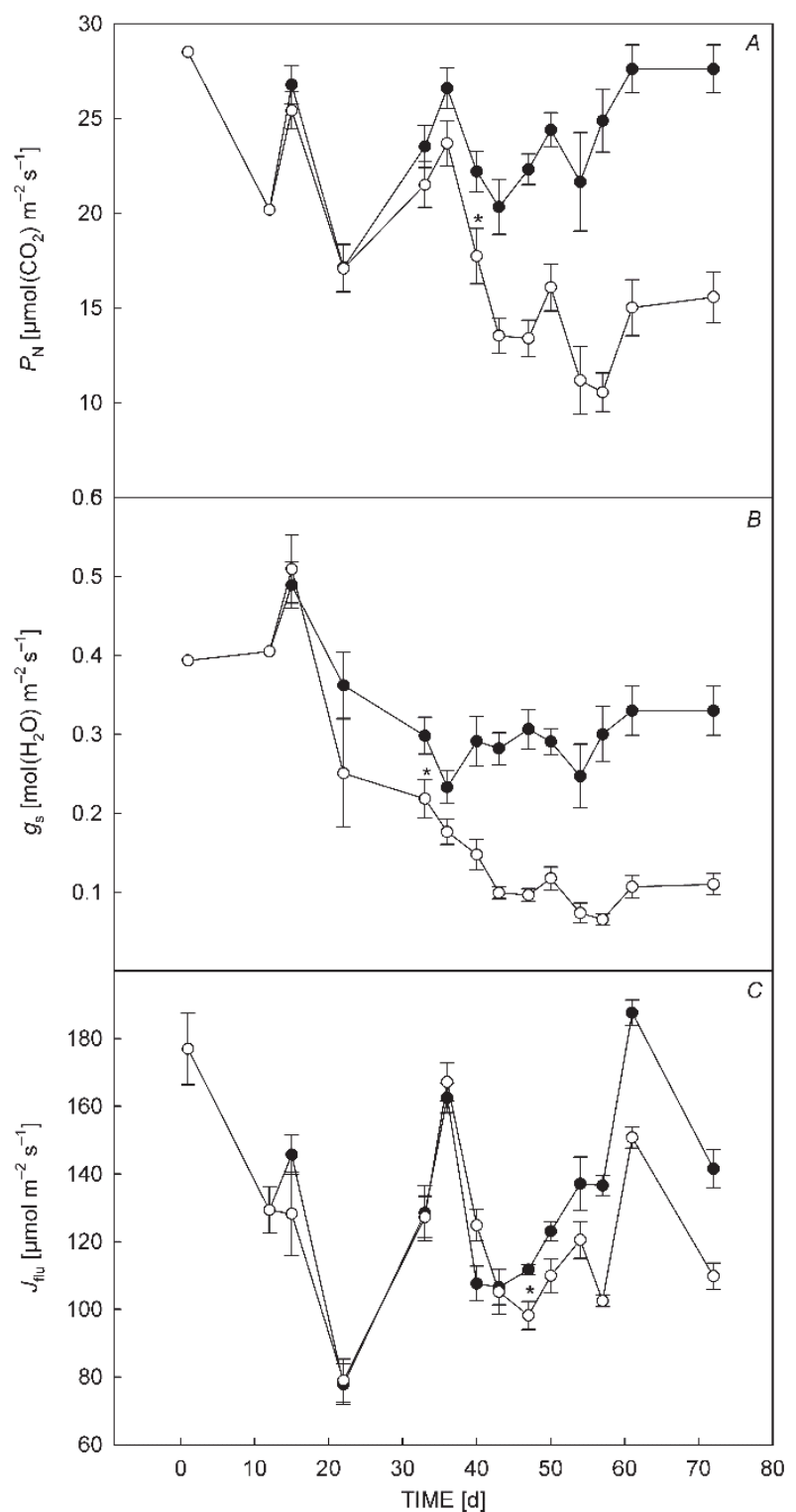

Fig. 3. Time course of net photosynthetic rate $\left(P_{\mathrm{N}}, A\right)$, stomatal conductance $\left(g_{\mathrm{s}}, B\right)$, and electron transport rate $\left(J_{\mathrm{flu}}, C\right)$ along the experiment in well-watered plants (black circles) and waterdeficit Arundo donax plants (white circles). Values are the means of 12 replicates. * - the first measure day in which values were significantly different between treatments $(p<0.05)$.

optimizing the water supplies during that critical moment in areas where water is the most limiting factor in plant production.

Regarding to the soil water conditions, the progressive water deficit imposed (thus a slow depletion of the soil water content, which allowed the acclimation of plants) and the low vapor pressure deficit (VPD) registered during the experiment led to a moderate water stress despite soil water content being as low as $20 \%$ of FC. Those conditions, moderate water deficit and low VPD, are similar to those observed in several Mediterranean areas during autumn and early spring in dry years; the areas and seasons where and when $A$. donax is usually planted (Angelini et al. 2005).

The biomass reduction under water deficit occurred mainly due to a decline in shoot biomass because root biomass did not significantly change under water deficit, which led to a lower $\mathrm{S} / \mathrm{R}$ ratio in the WD plants than that in WW ones (Table 2). The shoot biomass reduction appeared to be a consequence of both a lower number of tillers per plant and smaller leaves in the WD plantlets. Moreover, the WD plantlets showed a significantly lower SLA, as well as the reduction in plant leaf area and the leaf elongation rate, morphological and anatomical changes that led to a lower water consumption and an increased WUE in the WD plantlets (Hsiao et al. 1976, Meier and Leuschner 2008, Anjum et al. 2011). However, it is remarkable that such a reduction in $A$. donax plantlets was achieved by reducing the leaf size, with no effect on leaf number, because smaller leaves present lower transpiration requirements to reduce their temperature (Nobel 2009, Haworth et al. 2017).

Although the leaf elongation rates decreased under the WD conditions (Table 3), the leaves continued to grow until the end of the experiment under low soil water content and at a leaf water potential as low as $-1.0 \mathrm{MPa}$ at predawn and $-2.5 \mathrm{MPa}$ at midday. The osmotic potential differences between the WD and WW plants registered with relatively low changes in the RWC (Fig. 2B,C) suggests that most of those differences were due to active solute accumulation, i.e. osmotic adjustment, in the WD plants (Wright et al. 1997, Babu et al. 1999). Osmotic adjustment has been reported to contribute to maintain turgor in cells, which is necessary to maintain an active growth in water stressed plants (Hsiao et al. 1976, Morgan 1984). Likewise, modification of turgor would contribute to the ability of $A$. donax plantlets to maintain leaf elongation and, thus, plant growth under low soil water content and leaf water potential. Indeed, the WD plantlets showed an estimated turgor pressure (water potential osmotic potential) of $0.7 \mathrm{MPa}$ at predawn, although it was close to $0 \mathrm{MPa}$ at midday.

The SLA reduction in the WD plants suggests an increase in leaf density and/or leaf thickness as acclimation to reduce the water losses (Liu and Stützel 2004, Villagra and Cavagnaro 2006, Wu et al. 2008). Such leaf anatomical acclimation used to be observed in droughtadapted species that are able to show phenotypic plasticity (Villagra and Cavagnaro 2006, Wu et al. 2008, Gulías et al. 2009). As a consequence of the effects of WD on the biomass partitioning and SLA, the relative biomass investment in the leaves (i.e. LMR) and the relative leaf area per plant biomass (i.e. LAR) significantly decreased in the WD plantlets (Table 2). However, LAR showed a higher reduction than LMR, 33\% and 15\%, respectively, due to the SLA decrease under the WD conditions. Indeed, a low SLA has been linked to both low growth rates and high resource-use efficiencies (Poorter et al. 1990, Reich et al. 1997, Wright et al. 2001). The plasticity of $A$. donax 
Table 4. Mean values of the photosynthetic parameters analyzed. $P_{\mathrm{N}}-$ net photosynthetic rate; $g_{\mathrm{s}}-$ stomatal conductance to $\mathrm{H}_{2} \mathrm{O}$; chloroplast $\mathrm{CO}_{2}$-compensation point $\left(\mathrm{r}^{*}\right) ; g_{\mathrm{m}}-$ mesophyll conductance; $C_{\mathrm{i}}-$ substomatal $\mathrm{CO}_{2}$ concentration; $C_{\mathrm{c}}-$ chloroplastic $\mathrm{CO}_{2}$ concentration; $V_{\mathrm{c}, \max }\left(\mathrm{C}_{\mathrm{c}}\right)$ - maximum velocity of carboxylation calculated from gas exchange on a $C_{\mathrm{c}}$ basis; $J_{\max }\left(\mathrm{C}_{\mathrm{c}}\right)-\operatorname{maximum}$ capacity for electron transport calculated from gas exchange on a $C_{\mathrm{c}}$ basis; four $P_{\mathrm{N}}-C_{\mathrm{i}}$ curves per treatment were done. Data are means \pm SE of 12 replicates per treatment. * - statistically significant differences $(p<0.05)$ between well-watered (WW) and water-deficit (WD) plantlets.

\begin{tabular}{lll}
\hline Parameter & WW & WD \\
\hline$P_{\mathrm{N}}\left[\mu \mathrm{mol}\left(\mathrm{CO}_{2}\right) \mathrm{m}^{-2} \mathrm{~s}^{-1}\right]$ & $25.88 \pm 1.61$ & $15.45 \pm 3.22^{*}$ \\
$g_{\mathrm{s}}\left[\operatorname{mol}\left(\mathrm{H}_{2} \mathrm{O}\right) \mathrm{m}^{-2} \mathrm{~s}^{-1}\right]$ & $0.170 \pm 0.02$ & $0.067 \pm 0.01^{*}$ \\
$\mathrm{r}^{*}$ & 37.7 & 48.8 \\
$g_{\mathrm{m}}$ fluo $\left[\mathrm{mol}\left(\mathrm{CO}_{2}\right) \mathrm{m}^{-2} \mathrm{~s}^{-1}\right]$ & $0.626 \pm 0.08$ & $0.530 \pm 0.15$ \\
$g_{\mathrm{m}}$ Sharkey $\left[\mathrm{mol}^{2}\left(\mathrm{CO}_{2}\right) \mathrm{m}^{-2} \mathrm{~s}^{-1}\right]$ & $0.528 \pm 0.04$ & $0.418 \pm 0.15$ \\
$C_{\mathrm{i}}\left[\mu \mathrm{mol} \mathrm{mol} \mathrm{mol}^{-1} \mathrm{air}\right]$ & $218.15 \pm 14.34$ & $150.58 \pm 4.871^{*}$ \\
$C_{\mathrm{c}}\left[\mu \mathrm{mol} \mathrm{mol}{ }^{-1}\right.$ air $]$ & $173.88 \pm 14.93$ & $117.23 \pm 9.13^{*}$ \\
$V_{\mathrm{c}, \max }\left(\mathrm{C}_{\mathrm{c}}\right)$ Harley $\left[\mu \mathrm{mol} \mathrm{m}^{-2} \mathrm{~s}^{-1}\right]$ & $111.5 \pm 4.57$ & $106.1 \pm 9.06$ \\
$V_{\mathrm{c}, \max }\left(\mathrm{C}_{\mathrm{c}}\right)$ Sharkey $\left[\mu \mathrm{mol} \mathrm{m}^{-2} \mathrm{~s}^{-1}\right]$ & $150.04 \pm 9.28$ & $126.08 \pm 52.59$ \\
$J_{\max }\left(\mathrm{C}_{\mathrm{c}}\right)$ Harley $\left[\mu \mathrm{mol} \mathrm{m}^{-2} \mathrm{~s}^{-1}\right]$ & $202.2 \pm 6.90$ & $152.1 \pm 20$ \\
$J_{\max }\left(\mathrm{C}_{\mathrm{c}}\right)$ Sharkey $\left[\mu \mathrm{mol} \mathrm{m}^{-2} \mathrm{~s}^{-1}\right]$ & $182.40 \pm 1.93$ & $137.85 \pm 33.52$ \\
\hline
\end{tabular}

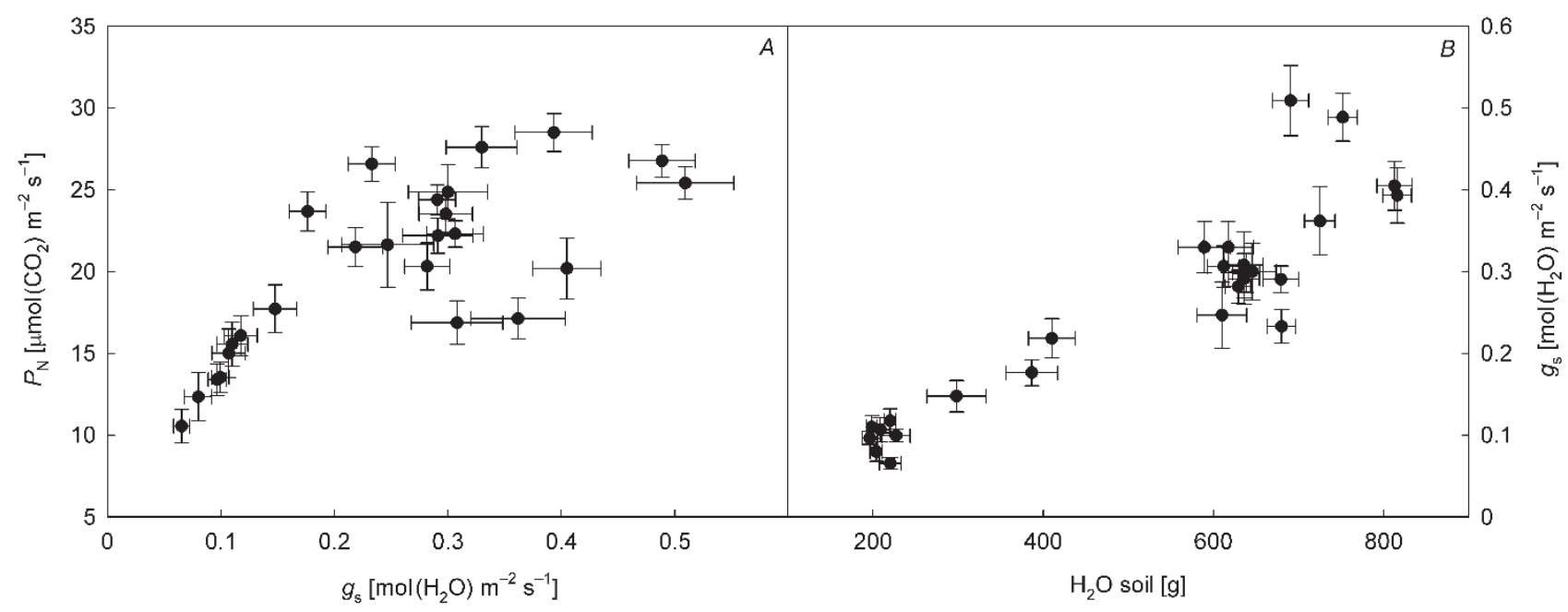

Fig. 4. Relationship between net photosynthetic rate $\left(P_{\mathrm{N}}\right)$ and stomatal conductance $\left(g_{\mathrm{s}}\right)(A)$ as well as between $g_{\mathrm{s}}$ and soil water content (B) in Arundo donax plantlets.

plantlets to produce smaller leaves with lower SLA under WD conditions would be a key component in its ability to cope with water stress. In this sense, the WUE at the plant level of the WD plants showed a significant increase in comparison to the WW plants.

The WD plantlets showed an early response to drought through a reduction in $g_{\mathrm{s}} 10 \mathrm{~d}$ before the $P_{\mathrm{N}}$ reduction in the WD plantlets (Fig. $3 A, B$ ). Several studies have reported earlier stomatal closure than $P_{\mathrm{N}}$ depletion as a consequence of water deficit in various species (Medrano et al. 2002, Flexas et al. 2004), which leads to an increase in the intrinsic water-use efficiency $\left(\mathrm{WUE}_{\mathrm{i}}\right)$, significantly increased $W E_{i}$ by a $43 \%$, from $88.97 \pm 5.29$ to $154.78 \pm$ 10.13 in the WW and WD plantlets, respectively (data not shown). The high $\mathrm{WUE}_{\mathrm{i}}$ in WD plantlets is in accordance with low biochemical limitations to $P_{\mathrm{N}}$. In this sense, Flexas et al. (2004) reported that $\mathrm{WUE}_{\mathrm{i}}$ increased under moderate water deficit is dominated by diffusive limitations to $P_{\mathrm{N}}$ as a consequence of relatively higher $g_{\mathrm{s}}$ than $P_{\mathrm{N}}$ reduction. In contrast, $W_{U} E_{i}$ decreases greatly under severe water stress, when photosynthetic biochemical limitations are higher than diffusive ones (Flexas et al. 2004). The significant and negative correlation between SLA and both $P_{\mathrm{N}} / g_{\mathrm{s}}$ and $\mathrm{WUE}_{\mathrm{p}}$ (Table $1 \mathrm{~S}$, supplement available online) supports the important contribution of such an anatomical acclimation to the increase in WUE.

The high plantlet growth rate during the first year of plantation has been reported to be a key point to ensure high productivity during the following years in $A$. donax (Pilu et al. 2013). Such high growth rate used to be ensured by fertilization and irrigation under Mediterranean conditions. Nevertheless, if $A$. donax is to be a useful species in Mediterranean marginal lands, where water availability for irrigation is generally low, it is extremely 
important to maximize not only the plant biomass accumulation but also its efficient use of resources. In addition, the trade-off between growth rate and water-use efficiency within and among species is widely reported (French and Schultz 1984, Fernández and Reynolds 2000, Condon et al. 2002). However, our results showed that it is possible to reduce the stomatal conductance without a significant reduction of the net photosynthesis in $A$. donax plantlets (Fig. 4A). For instance, $\mathrm{WUE}_{\mathrm{i}}$ would be the highest one when $g_{\mathrm{s}}$ values are approximately $0.2 \mathrm{~mol} \mathrm{~m}^{-2}$ $\mathrm{s}^{-1}$ (Fig. 4A). Similar opportunities of maximizing WUE have been reported in other crops (Pou et al. 2008, Tomás et al. 2012). In the present study, the $g_{\mathrm{s}}$ values were registered when the total soil water content was approximately $400 \mathrm{ml}$ (Fig. $4 B$ ). The precise amount of soil water needed to maintain the $g_{\mathrm{s}}$ would depend on several factors, such as plant leaf area, VPD, and soil characteristics; however, the significant regression between $g_{\mathrm{s}}$ and soil water content reported in this study $\left(R^{2}\right.$ $=0.84$ and $p<0.0001$, Fig. $4 B$ ) suggests the possibility of a reliable estimation of $g_{\mathrm{s}}$ from the measurement of soil water content; a parameter which is more economically and practically favorable to leaf gas-exchange analysis under field conditions.

\section{References}

Angelini L.G., Ceccarini L., Bonari E.: Biomass yield and energy balance of giant reed (Arundo donax L.) cropped in central Italy as related to different management practices. - Eur. J. Agron. 22: 375-389, 2005.

Anjum S., Xie X., Wang L.: Morphological, physiological and biochemical responses of plants to drought stress. - Afr. J. Agr. Res. 6: 2026-2032, 2011.

Arcidiacono C., Porto S.M.C.: Life cycle assessment of Arundo donax biomass production in a mediterranean experimental field using treated wastewater. - J. Agric. Eng. 42: 29-38, 2012.

Babu R.C., Pathan M.S., Blum A., Nguyen H.T.: Comparison of measurement methods of osmotic adjustment in rice cultivars. - Crop Sci. 39: 150-158, 1999.

Bell G.P.: Ecology and management of Arundo donax, and approaches to riparian habitat restoration in southern California. - In: Brock J (ed.): Plant Invasions: Studies from North America and Europe. Pp. 103-113. Backhuys, Leiden 1997.

Bernacchi C.J., Portis A.R., Nakano H. et al.: Temperature response of mesophyll conductance. Implications for the determination of rubisco enzyme kinetics and for limitations to photosynthesis in vivo. - Plant Physiol. 130: 1992-1998, 2002.

Condon A.G., Richards R.A., Rebetzke G.J., Farquhar G.D.: Improving intrinsic water-use efficiency and crop yield. - Crop Sci. 42: 122-131, 2002.

Fernández R.J., Reynolds J.F.: Potential growth and drought tolerance of eight desert grasses: lack of a trade-off? Oecologia 123: 90-98, 2000.

Flexas J., Bota J., Cifre J. et al.: Understanding down-regulation of photosynthesis under water stress: future prospects and searching for physiological tools for irrigation management. Ann. Appl. Biol. 144: 273-283, 2004.
Conclusions: Arundo donax has been reported to be a water-stress-tolerant species at the adult stage, which is partially due to the ability of its rhizome to accumulate water and nutrients. However, little is known regarding the ability of $A$. donax to cope with water-limited conditions at early stages, when the rhizome has not been developed yet. In this study, A. donax showed a great ability to tolerate moderate water stress. The plantlets reduced their water consumption to a larger extent than their biomass accumulation, which led to higher water-use efficiency in the water-deficit plantlets than in the well-watered ones. Such an increment was achieved by decreasing the leaf size and the specific leaf area in addition to the reduction of the stomatal conductance. As a result, both $\mathrm{WUE}_{\mathrm{i}}$ and $\mathrm{WUE}_{\mathrm{p}}$ significantly increased. Moreover, $A$. donax leaves showed an osmotic adjustment that clearly contributed to maintain leaf elongation under low soil water content. The reported reduction of $g_{\mathrm{s}}$ with a low variation in $P_{\mathrm{N}}$ and the highly significant regression between $g_{\mathrm{s}}$ and the soil water content suggest the possibilities of precise irrigation practices to optimize the water-use efficiency under field conditions in Mediterranean marginal lands, where water availability largely limits using $A$. donax as a biomass source.

Flexas J., Diaz-Espejo A., Galmés J., et al.: Rapid variations of mesophyll conductance in response to changes in $\mathrm{CO}_{2}$ concentration around leaves. - Plant Cell Environ. 30: 12841298, 2007.

French R.J., Schultz J.E.: Water use efficiency of wheat in a Mediterranean-type environment. The relation between yield, water use and climate. - Aust. J. Agr. Res. 35: 743-764, 1984.

Galmés J., Medrano H., Flexas J.: Photosynthetic limitations in response to water stress and recovery in Mediterranean plants with different growth forms. - New Phytol. 175: 81-93, 2007.

Grassi G., Magnani F.: Stomatal, mesophyll conductance and biochemical limitations to photosynthesis as affected by drought and leaf ontogeny in ash and oak trees. - Plant Cell Environ. 28: 834-849, 2005.

Gulías J., Cifre J., Jonasson S. et al.: Seasonal and inter-annual variations of gas exchange in thirteen woody species along a climatic gradient in the Mediterranean island of Mallorca. Flora 204: 169-181, 2009.

Harley P.C., Thomas R.B., Reynolds J.F., Strain B.R.: Modelling photosynthesis of cotton grown in elevated $\mathrm{CO}_{2}$. - Plant Cell Environ. 15: 271-282, 1992.

Haworth M., Centritto M., Giovannelli A. et al.: Xylem morphology determines the drought response of two Arundo donax ecotypes from contrasting habitats. - GCB Bioenergy. 9: 119-131, 2017.

Hsiao T.C., Acevedo E., Fereres E., Henderson D.W.: Water stress, growth, and osmotic adjustment. - Philos. T. R. Soc. B 273: 479-500, 1976.

Kang S., Post W.M., Nichols J.A. et al.: Marginal lands: concept, assessment and management. - J. Agr. Sci. 5: 129-139, 2013.

Lambert A., Dudley T., Saltonstall K.: Ecology and impacts of the large-statured invasive grasses Arundo donax and 
Phragmites australis in North America. - Invas. Plant Sci. Mana. 3: 489-494, 2010.

Lewandowski I., Scurlock J.M.O., Lindvall E., Christou M.: The development and current status of perennial rhizomatous grasses as energy crops in the US and Europe. - Biomass Bioenerg. 25: 335-361, 2003.

Liu F., Stützel H.: Biomass partitioning, specific leaf area, and water use efficiency of vegetable amaranth (Amaranthus spp.) in response to drought stress. - Sci. Hortic.-Amsterdam 102: 15-27, 2004.

Mann J.J., Kyser G.B., Barney J.N., DiTomaso J.M.: Assessment of aboveground and belowground vegetative fragments as propagules in the bioenergy crops Arundo donax and Miscanthus $x$ giganteus. - Bioenerg. Res. 6: 688-698, 2013.

Medrano H., Escalona J.M., Bota J. et al.: Regulation of photosynthesis of $\mathrm{C} 3$ plants in response to progressive drought: stomatal conductance as a reference parameter. - Ann. Bot.London 89: 895-905, 2002

Meier I.C., Leuschner C.: Leaf size and leaf area index in Fagus sylvatica forests: competing effects of precipitation, temperature, and nitrogen availability. - Ecosystems 11: 655-669, 2008.

Morgan J.M.: Osmoregulation and water stress in higher plants. - Annu. Rev. Plant Physio. 35: 299-319, 1984.

Niinemets U., Cescatti A., Rodeghiero M., Tosens T.: Complex adjustments of photosynthetic potentials and internal diffusion conductance to current and previous light availabilities and leaf age in Mediterranean evergreen species Quercus ilex. - Plant Cell Environ. 29: 1159-1178, 2006.

Nobel P.S.: Physicochemical and Environmental Plant Physiology, $3^{\text {rd }}$ ed. Pp. 540. Academic Press, Oxford 2009.

Paredes D., Trigo R.M., Garcia-Herrera R., Trigo I.F.: Understanding precipitation changes in Iberia in early spring: Weather typing and storm-tracking approaches. - J. Hydrometeorol. 7: 101-113, 2006.

Parry M., Flexas J., Medrano H.: Prospects for crop production under drought: research priorities and future directions. - Ann. Appl. Biol. 147: 211-226, 2005.

Peguero-Pina J.J., Flexas J., Galmés J. et al.: Leaf anatomical properties in relation to differences in mesophyll conductance to $\mathrm{CO}_{2}$ and photosynthesis in two related Mediterranean Abies species. - Plant Cell Environ. 35: 2121-2129, 2012.

Perdue R.E.: Arundo donax - Source of musical reeds and industrial cellulose. - Econ. Bot. 12: 368-404, 1958.

Pilu R., Badone F., Michela L.: Giant reed (Arundo donax L.): A weed plant or a promising energy crop? - Afr. J. Biotechnol. 11: 9163-9174, 2012.

Pilu R., Manca A., Landoni M.: Arundo donax as an energy crop: Pros and cons of the utilization of this perennial plant. Maydica 58: 54-59, 2013.
Poorter H., Remkes C.: Leaf area ratio and net assimilation rate of 24 wild species differing in relative growth rate. - Oecologia 83: 553-559, 1990

Pou A., Flexas J., Alsina M.M. et al: Adjustments of water use efficiency by stomatal regulation during drought and recovery in the drought-adapted Vitis hybrid Richter-110 (V. berlandieri $\times V$. rupestris). - Physiol. Plantarum 134: 313-323, 2008.

Reich P.B., Walters M.B., Ellsworth D.S.: From tropics to tundra: global convergence in plant functioning. - P. Natl. Acad. Sci. USA 94: 13730-13734, 1997.

Sánchez E., Gil S., Azcón-Bieto J., Nogués S.: The response of Arundo donax L. (C3) and Panicum virgatum (C4) to different stresses. - Biomass Bioenerg. 85: 335-345, 2016.

Sánchez E., Scordia D., Lino G. et al.: Salinity and water stress effects on biomass production in different Arundo donax L. clones. - Bioenergy Res. 8: 1461-1479, 2015.

Scordia D., Cosentino S.L., Lee J.W., Jeffries T.W.: Bioconversion of giant reed (Arundo donax L.) hemicellulose hydrolysate to ethanol by Scheffersomyces stipitis CBS6054. Biomass Bioenerg. 39: 296-305, 2012.

Shortall O.K.: "Marginal land" for energy crops: Exploring definitions and embedded assumptions. - Energ. Policy 62: 1927, 2013.

Stocker T.F., Qin D., Plattner G.K. et al.: Summary for policymakers. - In: IPCC: The Physical Science Basis. Contribution of Working Group I to the Fifth Assessment Report of the Intergovernmental Panel on Climate Change. Cambridge University Press, Cambridge, 2013.

Tomás M., Medrano H., Pou A. et al.: Water-use efficiency in grapevine cultivars grown under controlled conditions: Effects of water stress at the leaf and whole-plant level. - Aust. J. Grape Wine R. 18: 164-172, 2012.

Villagra P.E., Cavagnaro J.B.: Water stress effects on the seedling growth of Prosopis argentina and Prosopis alpataco. - J. Arid. Environ. 64: 390-400, 2006.

Webster R.J., Driever S.M., Kromdijk J. et al.: High C3 photosynthetic capacity and high intrinsic water use efficiency underlies the high productivity of the bioenergy grass Arundo donax. - Sci. Rep. 6: 20694, 2016.

Wright I.J., Westoby M.: Understanding seedling growth relationships through specific leaf area and leaf nitrogen concentration: generalizations across growth forms and growth irradiance. - Oecologia 127: 21-29, 2001.

Wright P., Morgan J.M., Jessop R.S.: Turgor maintenance by osmoregulation in Brassica napus and B. juncea under field conditions. - Ann. Bot.-London 80: 313-319, 1997.

Wu F., Bao W., Li F., Wu N.: Effects of drought stress and $\mathrm{N}$ supply on the growth, biomass partitioning and water-use efficiency of Sophora davidii seedlings. - Environ. Exp. Bot. 63: 248-255, 2008. 